\title{
The 21st Century "Maritime Silk Road" and the Construction of Teaching Chinese to Speakers of Other Languages Major in Guangxi
}

\begin{abstract}
Qianwei Jin ${ }^{1, *}$
${ }^{1}$ School of Arts and Cultural Communication, Guangxi University of Science and Technology, Liuzhou, Guangxi 545006, China

"Corresponding author. Email: 1909326837@qq.com

ABSTRACT

The construction of the "Maritime Silk Road" in the new era closely links Guangxi and ASEAN. As local colleges and universities in Guangxi, it is necessary to promote the development of Teaching Chinese to Speakers of Other Languages major and explore effective ways of educating people with high quality. The author believes that it is of great significance to combine Guangxi's geographical advantages towards ASEAN, and to promote the construction of the Teaching Chinese to Speakers of Other Languages major with a definite target. The main research contents are: first, the orientation of talent training must be scientific; second, based on the cultural differences of ASEAN countries, professional construction must guide students to fully shape the role of Chinese language teachers; third, it is a necessity to adhere to the concept of sustainable development and build a long-term effective education model. Using the literature method and typical case method to discuss, the conclusion is to actively cooperate with countries along the Maritime Silk Road to establish internship bases, undertake the responsibility of teaching Chinese to tell Chinese cultural stories, actively respond to the 21st century "Maritime Silk Road" initiative, and promote the high-quality construction of the Teaching Chinese to Speakers of Other Languages major in Guangxi.
\end{abstract}

Keywords: New Maritime Silk Road, Teaching Chinese to Speakers of Other Languages major, construction path

\section{INTRODUCTION}

Hepu, Guangxi is regarded as the starting point of the Maritime Silk Road in the Han Dynasty. General Secretary Xi Jinping has high hopes for Guangxi to build a new Maritime Silk Road and actively promote the economic and social development of China and

*Project: 2020 Guangxi Higher Education Undergraduate Teaching Reform Project: Research and Practice of Training Excellent Applied Talents in Local Colleges and Universities with "Intangible Heritage Master Dream Workshop" as an innovative and entrepreneurial teaching platform (No.: 2020JGA215); 2019 Guangxi Higher Education Undergraduate Teaching Reform Project: The Construction and Practice of a New Platform for Intangible Cultural Heritage Education for Art Majors in Local Colleges and Universities from the Perspective of "Three All-round Education" (Project No.: 2019JGB252); 2020 Guangxi University of Science and Technology "Curriculum Ideological and Political" Teaching Reform and

Research Special Project (Graduate Course): Exploration and Practice of Ideological and Political Reform of the Course "Intangible Cultural Heritage Protection Research" based on Blended Teaching (No.: 2020KCSZ26); 2020 "Curriculum Ideological and Political" Demonstration Course Construction Project of Guangxi University of Science and Technology: Chinese Folklore (No.: 2020KCSZ32).
ASEAN. As a local university in Guangxi, Guangxi University of Science and Technology has made full use of its geographical advantages in the district and its geographical advantages for ASEAN to promote the construction of the major of Teaching Chinese to Speakers of Other Languages. According to the policies and regulations of China and Guangxi, as well as the school's running practice, since 2009, the school has made achievements in education, teaching and scientific research that have been highly recognized and praised by the society. It is believed that Guangxi University of Science and Technology actively connects with ASEAN countries along the Maritime Silk Road, promotes the construction of Chinese international education with distinctive characteristics and gratifying results, follows the laws of education and teaching, and has built a high-quality education system through the joint efforts of teachers and students. The achievements are shown as the following aspects: scientifically positioning talent training, revising and improving the talent training plan, emphasizing the adaptive shaping of the role of Chinese teaching 
teachers, organizing teachers and students to consolidate the work foundation of foreign practice bases, and actively carring out learning cooperation and friendly exchanges, which are highly praised by Sinoforeign cooperation in running schools.

\section{Positioning TAlent TRAINING SCIENTIFICALLY}

Colleges and universities in Guangxi cultivate outstanding students majoring in Teaching Chinese to Speakers of Other Languages and shoulder the burden of Chinese teaching and cultural exchanges. They need to use a complete professional construction system to lay a solid foundation and improve their abilities. Among them, it is very important to find a talent training path suitable for self-construction and development. The orientation of talent training must be scientific. After nearly 10 years of work practice and exploration, the researchers gradually perfecting provides a feasible plan for students to engage in Chinese language education in ASEAN.

\section{A. Clearing the goals and following the rules}

Guangxi colleges and universities serve the national development strategy, especially the major of Teaching Chinese to Speakers of Other Languages. They must use their own discipline advantages to build cooperative learning platforms in China and foreign countries, adhere to the educational ideology of educators, convey the firm belief of win-win cooperation and development, clarify scientific and feasible education goals, and consciously use the laws of education and teaching to lay a solid foundation for national development and international cooperation. The major of Teaching Chinese to Speakers of Other Languages major of Guangxi University of Science and Technology started late, the enrollment scale is small, and it is in a local university that focuses on engineering. However, the teachers and students of Guangxi University of Science and Technology have gradually figured out a path suitable for their own development based on the actual situation of Guangxi: People in Guangxi must serve the economy and society of Guangxi, and the cultivation of outstanding professionals is not only about learning cultural knowledge, but also applying what they have learned and dare to innovate and develop. Therefore, the talent training plan formulated by this major has determined the guiding ideology for ASEAN to serve the countries along the Maritime Silk Road. According to the survey, the proportion of students majoring in Teaching Chinese to Speakers of Other Languages in some universities has not reached the ideal target. This obviously does not conform to the law of running a school, nor can it test the students' practical application ability. From the beginning of the school, Guangxi University of Science and Technology actively visited and asked for advice, especially actively cooperating with local governments and ASEAN countries, and vigorously hosting foreign internship bases. To ensure that students' learning and application are fully connected, they must not miss the link of real Chinese teaching in foreign countries. It is necessary to strictly guarantee the formation of students' abilities through procedures that conform to the laws of education and teaching and to implement actions when realizing this point. After many efforts, Guangxi University of Science and Technology has established 6 practice bases with ASEAN Thailand, Malaysia, Cambodia, Indonesia, Vietnam, etc., which are enough to ensure that all students can go to relevant countries for Chinese teaching under normal circumstances.

\section{B. Increasing knowledge reserves and improving talent training programs}

The contemporary college students are one person who embodies the temperament of the entire country. That is to say, the quality of college students is directly related to the image of the country. It is still a must to consciously assume the glorious duty of spreading the country's positive energy and tell the story of China, especially the story of China's recent achievements and the continuous progress of China's reform and opening up. Students majoring in Teaching Chinese to Speakers of Other Languages should engage in Chinese teaching practice in the country before graduation, and even work in foreign counties for a long time after graduation. In order to lay a solid foundation for students, it is necessary to increase the cultural knowledge reserves of the country where they would stay. To make comprehensive preparations for the smooth implementation of Chinese language teaching, the school revise and improve the talent training plan, especially the addition of highly targeted courses such as "Cross-Cultural Communication", "Southeast Asian Culture", and "Thai Language". After the teaching and training of professional teachers, students can acquire the knowledge of ASEAN culture and geography, especially the cultural differences of different countries, and become popular college students who represent the positive image of the country. It is important to be educated, reasonable and knowledgeable. It should be said that regardless of whether they go abroad or not, college students should earnestly read and study, and become a person with good overall quality of cultural accomplishment, full of love, self-confidence, curiosity, strong sense of cooperation, and good creative ability. Internship students in the foreign countries should be aware of the special culture of the country where they are located. They are tolerant and cooperative, can integrate into the teachers and students of the local schools as soon as possible, become good hands in teaching Chinese in the classroom, and have been highly recognized by the teachers and students in the 
local schools. Some students also actively write articles related to their countries, and publish them in local newspapers, becoming a testimony of friendly exchanges between China and foreign countries.

\section{Paying attention to the key points and grasping the key}

To formulate a talent training plan, the positioning must be scientific. It is a must pay attention to grasp the key points and clarify the issues of who the major of Teaching Chinese to Speakers of Other Languages is to train and who will serve. The colleges and universities in China enroll more than 7 million college students every year. It is through college education to cultivate outstanding young talents who are responsible for the great rejuvenation of the Chinese nation. It can be said that this is an important goal of educating people and the starting point for running colleges and universities. Therefore, the major of Teaching Chinese to Speakers of Other Languages is no exception. The college students trained in China should be upright Chinese, and Chinese with the unity of knowledge and action. The unity of knowledge and action here emphasizes knowledge, ability and action. Once the goal is determined, they can do their best to complete it, and they will not waver or be discouraged in the completion process, boldly try and dare to innovate and seek success. As a result, it is very important to set up certain courses of Chinese culture and strengthen the consciousness of the Chinese nation community. Guangxi University of Science and Technology sets the curriculum such as "Introduction to Chinese Studies", "History of Chinese Thoughts", "Chinese Talents", etc., through systematic learning to strengthen a high degree of self-confidence in Chinese culture. There are cultural differences between different ethnic groups, but that is part of the excellent culture of the entire Chinese nation. In the future, Chinese will continue to create new multicultural cultures that belong to all Chinese people. This point must be clearly understood and the relationship between the whole and part of the Chinese nation must be grasped. In addition, the talent training program should strengthen the status of core courses and basic courses to ensure that students can shape educational roles with a complete knowledge structure through learning. Therefore, courses such as language, literature, and pedagogy must maintain a central position to ensure that students are proficient in Chinese learning. This is the foundation of students' cultural knowledge. It is not reasonable to make the increasing of the target country's knowledge reserve to affect the construction of basic courses because of the internship in foreign countries.

\section{FULLY SHAPING THE ROLE OF TEACHERS}

People don't have the knowledge by birth, and they have to learn and practice to acquire knowledge in order to master the corresponding cultural knowledge and perform the duties mastered by the job. It is satisfying to adapt and be able to do the job, and to achieve outstanding results in the completion of the work, but this is likely to require a long work trial. Majors of Teaching Chinese to Speakers of Other Languages usually go out for internship in the 7th semester, write a graduation thesis defense in the 8th semester, and then move to the job. Chinese primary and middle school education still requires a period of training, let alone direct internships in foreign countries during the study period, and they are different countries with differences in language and culture. Therefore, adapting to the role of a teacher is a very difficult task. As a result, Guangxi University of Science and Technology has carried out a large number of practical activities inside and outside the class to actively cultivate the ability of students to teach.

\section{A. Cultivation of teachers' role in class}

Intelligent technology is widely used, teachers and students have the same opportunity to obtain information, and because of their energetic, simple thinking, and strong curiosity, students use the Internet to learn more information than teachers. This forces teachers not only to have rich cultural knowledge, especially university teachers must learn to be rich, but also to apply advanced teaching methods flexibly. That is to say, the classroom content needs to be rich, the methods need to be suitable for the students to like, the student's status as the main body of learning needs to be respected, and the students' sense of innovation and creativity need to be cultivated, being the high-quality curriculum teaching. One of them is to set aside a certain amount of classroom time to students, increase the students' reading or practice workload. Through a large amount of extracurricular learning, the reading or practice can be transformed into a personal knowledge reserve and can be used flexibly, allowing students to try classroom teaching through personal preparation. This is a very good role shaping of teachers in class. Obviously, university teachers read a lot and have relatively rich work experience, especially teachers with strong scientific research capabilities far beyond the level of student learning. Sometimes people can see that individual teachers like to fill the classroom with duck-filling teaching because it saves a lot of trouble and even ignores the feelings of the students. This requires teachers to change their teaching methods. It is necessary to give students more learning space through classroom trial lectures, so that students can learn to learn and accumulate learning experience, especially with creative learning transformation. Students can also exercise their courage through lectures, cultivate teaching methods, and learn to deal with teaching problems flexibly, so as to lay the foundation for real teaching work in the future. Teachers and students interact actively to create opportunities for students to 
improve and guide students to learn teaching skills and abilities.

\section{B. A variety of extracurricular activities to cultivate teaching skills}

The university campus is rich and colorful, and various activities are particularly numerous. It is necessary to carefully identify and participate in suitable extracurricular activities. In fact, the teacher's level of lectures cannot completely rely on special training methods, and the teachers can use various occasions and opportunities to exercise. Because teacher-student teaching and learning is a special kind of interpersonal communication, it is necessary to complete the relevant teaching objectives within a specific time, and to use appropriate methods to enable the educated to gain true knowledge and achieve better learning results. As it known to all, interpersonal communication skills require a long time of learning and exercise. Older people are often better at socializing. Youth and children generally have insufficient experience in dealing with people, and these make teachers need more knowledge and experience. Students in school are mainly learning cultural knowledge, and there are few opportunities to be teachers. Therefore, they should make good use of extracurricular activities to exercise. The first is to use one's own strengths, especially those programs such as recitation, singing and dancing. Universities often hold singing and dancing activities on specific festive occasions, such as welcome party and New Year's Day party. If there is no singing and dancing skills, students can rehearse skits, dramas and other active performances, mainly to exercise courage. The second is to participate in exchanges between Chinese and foreign students, and to narrow the distance between Chinese and foreign students by showing Chinese talents. They don't have to be good at calligraphy and calligraphy, they can show what they are best at. For example, students from the north make dumplings, students from the south make colorful rice, and even that they can climb trees and show them, as long as it can set off the atmosphere, make participants feel interesting, and attract friendly exchanges with peers. These activities are not difficult. Everyone can participate, accumulate experience and skills in interacting with others, and tap their own potential. They may find personal strengths. These can play a positive role in their teaching in the future.

\section{The school should actively create a cultural environment that values teaching}

Respecting teachers and teaching can cultivate more outstanding talents and support the healthy and scientific development of society. Colleges and universities must consciously take measures to improve teachers' remuneration and status, so that teachers are willing to teach with peace of mind, and take the cultivation of more outstanding talents as the highest honor. The first is to attach importance to frontline teachers. Based on research materials and combined with its own reality, Guangxi University of Science and Technology has formulated work regulations suitable for schools and individuals, which fully reflects the work policy of focusing on teaching and driving development through research. Taking the Teacher's Day commendation of outstanding teachers as an example, the selection of outstanding teachers must first satisfy the outstanding teachers who are indeed engaged in teaching jobs. No matter how high the management level is, they cannot be rated as outstanding teachers, ensuring that the honor of famous teachers belongs to frontline teachers. This sends a clear signal that teachers are very hard at teaching. Not only do they perform their job duties, they must also ensure that the teaching students are satisfied, and pay attention to appropriate teaching methods, which can stimulate students' interest in learning and explore their creative talents. The second is to hold a teaching competition in which students participate, mainly to provide opportunities for Teaching Chinese to Speakers of Other Languages majors to exercise their talents, and at the same time to attract students to consciously improve their teaching ability, so that they can show their skills in the teaching competition. In order to improve the quality of teaching, Guangxi University of Science and Technology holds a young teacher competition and an excellent teaching competition every year. These can mobilize students to actively listen, learn the teaching skills of outstanding teachers, and actively apply them to their own teaching. According to statistical data, most of the school's foreign Chinese teaching students perform well, and the recognition of the schools they teach has reached $83.7 \%$. The efforts of several years have been highly praised by each other.

\section{Constructing a SUSTAINABLE DEVELOPMENT MODEL}

Since enrolling students majoring in Teaching Chinese to Speakers of Other Languages in 2009, Guangxi University of Science and Technology has actively carried out foreign exchanges and gradually established a sustainable development model. The traditional culture of China especially respects the concept of sustainable development. The so-called "prosperity is the virtue" means to value long-term development of survival, that is, to take effective measures to ensure the sustainable development of all things. Indeed, there are only a few people who are engaged in Chinese teaching in foreign countries. According to the learning environment and the set goals, some countries do not have high requirements for Chinese teaching, and relatively speaking, the difficulty of teaching is not very high. However, the construction 
of Teaching Chinese to Speakers of Other Languages cannot be satisfied with simple listening, speaking, reading, and writing. Instead, it needs to actively explore sustainable education models of educating people. Guangxi University of Science and Technology adheres to the school-running ideas of ASEAN countries along the New Maritime Silk Road, and builds a sustainable development mechanism to ensure the continuous improvement of the quality of education.

\section{A. Strengthening the main management responsibilities}

The students majoring in Teaching Chinese to Speakers of Other Languages who have been sent to foreign countries cannot be effectively managed by relying on a single agreement alone. Guangxi University of Science and Technology has formulated a detailed management system with relevant ASEAN countries, especially for the strategy of taking practical actions, implemented the management responsibilities of foreign students to relevant internship schools, and formulated management plans according to different time periods and possible events. The first is to implement clearly the responsibilities of the internship school, and supervise and provide services from three meals and breaks in daily life to daily work. When students are teaching internships in Southeast Asian countries, there has been a problem that individual schools are unwilling to fulfill the agreement. They were originally responsible for the daily living allowances for students. However, when the students went to work there, they offered various reasons for not willing to pay student living allowances. Relevant teachers of Guangxi University of Science and Technology insisted on agreement management and stated their interests in the purpose of long-term cooperation. Finally, the internship school fulfilled its promise and won their own interests for the students. The second is to educate students on self-management, far away from thousands of rivers and mountains, it is indeed impossible to achieve close management. Especially in the event of an unpredictable emergency, students still need to actively solve it by themselves. Therefore, education should be strengthened during the study period in China, and students need to learn to deal with the emergency in a timely and proactive manner to get rid of dependence. And it is necessary to choose the team leader at each internship school, as a contact to unite everyone. It is believed that there is strength and wisdom in numbers. It is also necessary to respect the customs of the country where you live, and abide by its laws and regulations. If some people have something to do, they can discuss collectively, get through various difficulties together, and successfully complete the teaching work undertaken.

\section{B. Creating a virtual simulation experiment teaching project}

Modern media, especially smart phones, have brought everyone closer, and countries around the world have become a global village. As it known to all, massive amounts of information are available for inquiries at any time, making it easy to know all kinds of knowledge information. As a result, virtual technology is used to create teaching situations in ASEAN countries, exercise various abilities of students, and build a distinctive "Internet + " education path. The first is to actively use the teaching software developed and purchased by our teachers and the laboratory constructed to establish an advanced virtual simulation teaching laboratory. According to the different conditions of ASEAN countries, especially cultural differences, the school has implemented tailor-made teaching and training models for students majoring in Teaching Chinese to Speakers of Other Languages, mobilized experienced teachers to set up a knowledge base of teaching curriculum content, including teaching goals, key points, difficulties, as well as key points and solutions to problems, and sets up possible questioning links. After a lot of learning experience, it can help students master the teaching models and skills of different course contents as soon as possible, and improve the efficiency of training students' abilities. The second is to strengthen the efficiency of experimental teaching projects based on feedback information. Because there is still a gap between human-computer communication learning and real teaching, it is necessary to pay attention to timely statistics on the effective teaching experience provided by foreign internships, especially where improvements are worth noting. For example, human-computer interactive training often has no emotional factors in it, but real teaching brings eye contact with love. Teachers should engage in teaching according to the needs of students, integrate themselves into the students, and take the learning task as the greatest satisfaction, so that the students' learning enthusiasm can be improved. Therefore, experimental teaching projects should guide students to learn effective teaching methods, and it is best to train students to consciously form a personal teaching style.

\section{Lifelong education needs to be implemented consistently}

The best way to learn is lifelong education. The first is that the alma mater must keep track of students' learning applications, not only majoring in Teaching Chinese to Speakers of Other Languages, but many students who graduated out of the school will no longer have effective contact with the school after many years. Although there is an alumni association, it is difficult to feed back the various experiences in work and life to the school. In addition, the teachers have been replaced 
and leaders have been changed, graduation output and subsequent education gradually lose contact. Therefore, in order to better carry out their work, colleges and universities should not simply pass on advanced educational concepts, but should work hard to guide graduate students to visit their alma mater regularly every three or five years, so that information exchanges are not interrupted. Normally, it is necessary to strengthen the connection through Internet tools, and the enthusiastic students should do a good job summary of professional learning experience and various feelings of work application, hoping to provide some help to the professional construction of the alma mater.

The second is to pay attention to the connection between teachers and students. Through the Internet, teachers can grasp the real-time dynamics of foreign intern students, understand the students' psychology and emotions, and strengthen the connection with foreign internship schools to facilitate student management and solve various problems encountered in time. For example, student life is not suitable or work is not competent, etc. These are very tricky things. Therefore, teachers should adhere to the long-term close contact between teachers and students, communicate with students and internship schools in a timely and honest manner through the Internet, find solutions to solve these problems in a timely manner, so that students can effectively exercise and improve their own working ability, providing feasible solutions for lifelong education.

\section{CONCLUSION}

Guangxi local colleges and universities bear the glorious duty of serving the society. In order to strengthen the exchanges between China and foreign countries, according to the needs of ASEAN countries, it is of great significance to catch the wind of the construction of the Maritime Silk Road in the new era, and accelerate the development of the Teaching Chinese to Speakers of Other Languages major. In order to create a positive atmosphere of public opinion for the development of China-ASEAN cooperation, friendly exchanges, mutual benefit and win-win, it is necessary to scientifically position talents, formulate reasonable talent training plans, and comprehensively shape students to adapt to the role of Chinese teachers in accordance with the needs of ASEAN countries. It is also necessary to persist in the concept of sustainable development, have long been committed to the healthy and scientific development of the Chinese language education major, and actively explore an efficient mode of talent training that suits its own actual characteristics.

\section{References}

[1] Cui Xiliang, The Development and Prospect of Teaching Chinese as a Second Language and International Chinese Education [J]. Applied Linguistics, 2010 (2). (in Chinese)

[2] Wu Yinghui, On some TCSOL-related theories and practice [J]. Journal of Yunnan Normal University (Philosophy and Social Sciences Edition), 2016 (1). (in Chinese)

[3] Wan Xiaoming, Research on the International Promotion of Chinese in the Process of "The Belt and Road" [J]. Jiangxi Social Sciences, 2017 (4). (in Chinese)

[4] Wu Jian, Yang Jing, New Era, New Chinese, New Journey: The Development Trend of Chinese Education in Southeast Asia [J]. Journal of South China Normal University (Social Science Edition), 2018 (5). (in Chinese)

[5] Hong Liu, The Belt and Road Initiatives and Chinese Education in ASEAN Vountries [J]. Journal of Hebei Normal University, 2018 (2). (in Chinese)

[6] Li Ya, Xia Tian. Opportunities and Challenges of Chinese International Education and Chinese Culture Communication in Central Asia Against the Background of "the Belt and Road Initiative" [J]. Contemporary Education and Culture, 2019 (6). (in Chinese) 